OPEN ACCESS

Edited by: William C. Cho,

QEH, Hong Kong, SAR China

Reviewed by: Solaleh Emamgholipour, Tehran University of Medical

Sciences, Iran Yue Zhang, University of Montreal Hospital Centre (CRCHUM), Canada

*Correspondence:

Elham Abdollahi ea6112@gmail.com Houshang Rafatpanah Rafatpanahh@mums.ac.ir

Specialty section: This article was submitted to RNA,

a section of the journal Frontiers in Genetics

Received: 18 September 2021 Accepted: 01 November 2021 Published: 06 December 2021

Citation:

Li N, Saghafi N, Ghaneifar Z,

Rezaee SA, Rafatpanah $\mathrm{H}$ and Abdollahi $E$ (2021) Evaluation of the Effects of 1,25VitD3 on Inflammatory

Responses and IL-25 Expression.

Front. Genet. 12:779494.

doi: 10.3389/fgene.2021.779494

\section{Evaluation of the Effects of 1,25VitD3 on Inflammatory Responses and IL-25 Expression}

\author{
Nana $\mathrm{Li}^{1}$, Nafiseh Saghafi ${ }^{2}$, Zahra Ghaneifar ${ }^{3}$, Seyed Abdorahim Rezaee ${ }^{4,5,6}$, \\ Houshang Rafatpanah ${ }^{4,5,6 *}$ and Elham Abdollahi ${ }^{2,4 *}$
}

${ }^{1}$ Department of Obstetrics, Jinan Maternal and Child Care Health Hospital Affiliated to Shandong First Medical University, Jinan, China, ${ }^{2}$ Department of Gynecology, Woman Health Research Center, Mashhad University of Medical Sciences, Mashhad, Iran, ${ }^{3}$ Department of Nutrition, School of Medicine, Mashhad University of Medical Sciences, Mashhad, Iran, ${ }^{4}$ Department of Immunology and Allergy, School of Medicine, Mashhad University of Medical Sciences, Mashhad, Iran, ${ }^{5}$ Research Center for HIV/ AIDS, HTLV and Viral Hepatitis, Iranian Academic Center for Education, Culture, and Research (ACECR), Mashhad Branch, Mashhad, Iran, ${ }^{6}$ Inflammation and Inflammatory Diseases Research Center, School of Medicine, Mashhad University of Medical Sciences, Mashhad, Iran

VitD3 may contribute to a successful pregnancy through modulation of immune responses, so VitD3 deficiency may have a role in the immunopathogenesis of unexplained recurrent spontaneous abortion (URSA). However, the mechanisms of immunomodulatory actions of VitD3 in decreasing the risk of recurrent spontaneous abortion have not been understood well.

Objective: The purpose of this research was to investigate the influence of 1,25VitD3 on IL-25 and related cytokines of Th17 cells including IL-17A, IL-6, and IL-23 in peripheral blood mononuclear cells of healthy women as a control group and women with unexplained recurrent spontaneous abortion.

Method: Isolation of peripheral blood mononuclear cells (PBMCs) was performed from peripheral blood of the subjects of the studied groups (20 women with URSA as a case group, and 20 control women). The effects of 1,25VitD3 ( $50 \mathrm{nM}$, for $24 \mathrm{~h}$ ) on the studied parameters were evaluated and were compared to the positive and negative controls in vitro. Flow cytometry analysis was used to determine the percentages of regulatory T cells and Th17 cells. For gene expression measurement and cytokines assay, real-time PCR and ELISA were carried out.

Results: The proportion of Th17 cells in women with URSA was considerably higher than in the control group. IL-25 mRNA and protein levels in cultured PBMCs from women with URSA were lower than the controls. 1,25VitD3 increased IL-25 expressions at both the protein and mRNA levels in PBMCs from women with URSA relative to the control group. Additionally, 1,25VitD3 treatment not only significantly decreased the percentage of Th17 cells frequency but also reduced expressions of IL-6, IL-17A, and IL-23 in PBMCs from women with URSA.

Conclusion: 1,25VitD3 may diminish inflammatory responses cells via downregulation of IL-25 expression. It could be an interesting subject for future researches in the field of the immunopathology of URSA to identify molecular pathways in URSA treatment.

Keywords: URSA, VitD3, Th17 cells, IL-25, inflammation 


\section{INTRODUCTION}

One of the most serious pregnancy complications is unexplained recurrent spontaneous abortion (URSA), which refers to three or more consecutive pregnancy losses before 20 completed gestation weeks (Dimitriadis et al., 2020). URSA is usually $50 \%$ without any recognizable endocrine, genetic, infectious, and anatomical factor that affects $1-5 \%$ of fertile women (Dimitriadis et al., 2020; Giannubilo et al., 2012). Idiopathic abortions are caused by disrupted immune responses, according to new evidence (Guerin et al., 2009; Abdollahi et al., 2020a). Interleukin-25 (IL-17E) is a cytokine in the IL-17 family with a sequence that is $16-20 \%$ identical to that of IL-17A (Pan et al., 2001; Kolls and Lindén, 2004; Iwakura et al., 2011). In terms of structure and biological function, IL-25 is distinct from other members of the IL-17 family (Lee et al., 2001; Pan et al., 2001; Kolls and Lindén, 2004; Iwakura et al., 2011; Mantani et al., 2015). IL-25 is released by activated Th2 cells, bone marrow-derived mast cells, vascular endothelial cells, alveolar macrophages, basophils, and eosinophils (Fort et al., 2001; Pan et al., 2001; Kim et al., 2002; Wang et al., 2007; Divekar and Kita, 2015). Peripheral blood mononuclear cells (PBMCs), especially $\mathrm{CD}^{+} \mathrm{T}$ cells, are the main sources of IL-25 in the bloodstream (Licona-Limón et al., 2013; Fahy, 2015; Barati et al., 2020). CD $4^{+} \mathrm{T}$ cells, which include T helper 1 (Th1), Th2, regulatory $\mathrm{T}$ cells (Tregs), and Th17 cells, play an important role in the maternal immune response (Caruso et al., 2009; Saito et al., 2010; Figueiredo and Schumacher, 2016; Barad et al., 2017; Cyprian et al., 2019; Pei et al., 2019; Muyayalo et al., 2020).

Th17 cells elicit inflammatory reactions by producing cytokines such as IL-22, IL-21, IL-17A, IL-17 F, and TNFa as the pro-inflammatory cytokines (Veldhoen et al., 2006; Abdollahi et al., 2015a; Abdollahi et al., 2016a; Konkel et al., 2017; Fujimoto et al., 2020).

The active form of VitD3 $(1,25(\mathrm{OH}) 2 \mathrm{D} 3,1,25 \mathrm{VitD} 3)$ is a multi-target hormone (Heyden and Wimalawansa, 2018) that has a critical role in bone health by regulating calcium and phosphate homeostasis (Eisman et al., 1979; Makishima et al., 2002; Veldurthy et al., 2016). Beyond the classical function, it was found that upon binding to vitamin D receptor, VitD3 regulates function and differentiation of different immune cells including macrophages, $\mathrm{B}$ cells, dendritic cells, and $\mathrm{T}$ cells (Umar et al., 2018; Wang et al., 2020). VitD3 has been shown to contribute to decidualization and implantation via the modulation of inflammatory and immune responses leading to successful pregnancy (Luk et al., 2012; Dabrowski et al., 2015; Gonçalves et al., 2018; Martens et al., 2020). In 85\% of pregnant women, VitD3 deficiency is common and may be associated with an increased risk of pregnancy complications, such as preeclampsia, infertility, and abortion (Vijayendra Chary et al., 2015; Blomberg Jensen et al., 2016).

To our knowledge, no research has been carried on the evaluation of IL-25 expression and Th17 responses in PBMCs from women with URSA compared to the healthy women (as the controls) in the presence of 1,25 VitD3. In this study, we evaluated the frequency of Th17 cells, as well as the levels of IL-25, IL-17A, and IL-6 as related cytokines in PBMCs from women with URSA and controls, as well as the possible correlations.

\section{MATERIALS AND METHODS}

\section{Subjects}

This was a case-control study that was conducted from 2019 to 2021 on 20 non-pregnant women with RSA (the case group), and 20 fertile non-pregnant women (the control group). The controls had at least one normal delivery. Women in both the case and the control groups were at reproductive age and were not pregnant as indicated by a negative result in the blood HCG test. They were with regular menstruation, a normal BMI, and without any anatomical or genetic abnormalities. The women in the case group did not have any medical problems (except for RSA) and did not take any medication. The exclusion criteria for the case group were fewer than three consecutive miscarriages, positive screening tests such as hormone tests, viral infections (HIV, HBV and, HCV), agglutination assay (TPPA) for detection of antibodies against the causative agent of syphilis, autoantibodies (anti-phospholipid antibodies, antinuclear antibodies, anti-cardiolipin antibodies, lupus anticoagulant antibodies), female and male, and karyotypes.

Inclusion criteria for the case group were normal results in the mentioned lab test panel, VitD3 deficiency (less than $20 \mathrm{ng} / \mathrm{ml}$ ), as well as no consumption of vitamin D supplements in the previous 3 months.

Inclusion criteria for the controls were normal results in the routine lab test panel (as mentioned above), VitD3 deficiency, no consumption of vitamin D supplements in the previous 3 months, no history of miscarriage, and they had at least one healthy child.

Semen analysis was conducted for male partners of all studied women to ensure that sperm count, sperm shape, and movement were normal.

\section{Isolation of PBMCs}

PBMCs isolation was carried out by Ficoll, lymphosep (Biosera, UK) from $10 \mathrm{ml}$ of peripheral blood. After twice PBMC washing with PBS (phosphate-buffered saline, Sigma-Aldrich, Israel), $10^{6}$ cells/ml were cultured in media (RPMI-1640 with $10 \%$ heat-inactivated fetal calf serum (FCS), $100 \mathrm{U} / \mathrm{ml}$ Pen-Strep, $2 \mathrm{mM}$ L-Gln). For evaluation of cell viability, Trypan Blue dye exclusion was used.

\section{Optimization of 1,25VitD3 Concentration}

$1,25 \mathrm{VitD} 3(50 \mathrm{nM})$ for $24 \mathrm{~h}$ was selected as the optimized concentration and time of treatment. Six-well plates were used for PBMC culture $\left(2 \times 10^{5} / \mathrm{ml}\right.$ of media) with adding the different concentrations of $1,25 \mathrm{VitD} 3$ [10,30,50, $100 \mathrm{nM}$, and 0 (control)] for $12,24,48$ and $72 \mathrm{~h}$. Optimization of the concentration of $1,25 \mathrm{VitD} 3$ was achieved by assessing the proportion of Tregs and Th17 cells among isolated PBMCs from four women with RSA, using flow cytometry analysis FACS Calibur (BD, USA). 
TABLE 1 | Primer sequences used in real-time quantitative reverse transcriptase polymerase chain reaction analysis.

\begin{tabular}{|c|c|c|c|}
\hline Target gene & Sequence 5-3' & Purpose & Product length (bp) \\
\hline$\beta 2 \mathrm{M}$ & $\begin{array}{l}\text { 5'-TTGTCTICAGCAAGGACTGG-3' } \\
\text { 5'-CCACTTAACTATCTTGGGCTGTG-3' }\end{array}$ & Forward Reverse & 127 \\
\hline IL-25 & $\begin{array}{l}\text { 5'-ACTACTTCAAGTTCCACAACATGC-3' } \\
\text { 5'GAGTGTCCGCTGCTTCTCTG-3' }\end{array}$ & Forward Reverse & 112 \\
\hline
\end{tabular}

\section{Cell Culture}

PBMC $\left(2 \times 10^{6} /\right.$ subject $)$ was seeded in each well of six well plates. For each subject (for flow cytometry and real-time PCR analyses), there were four experiments as described in the previously published study (Abdollahi et al., 2020b): 1. with 1,25VitD3 (Sigma, Israel, $50 \mathrm{nM}$ for $24 \mathrm{~h}$ ) treatment; 2. with PHA (Gibco Company, USA, $10 \mu \mathrm{M}$ ) treatment; 3 . with the media only (as the baseline), 4. uncultured PBMCS.

\section{Flow Cytometry Detection of Th17 Cells}

PBMCs $\left(1 \times 10^{6}\right)$ were treated with $50 \mathrm{ng} / \mathrm{ml}$ PMA (eBioscience, USA) and $1 \mu \mathrm{g} / \mathrm{ml}$ ionomycin (eBioscience, USA) to stimulate for intracellular cytokine production (for $5 \mathrm{~h}$ in the presence of brefeldin $\mathrm{A}$ (eBioscience, USA) at $37^{\circ} \mathrm{C}$ and $5 \% \mathrm{CO}_{2}$ ). After that, cells were stained for surface of the markers with antiCD8 conjugated with FITC and anti-CD3 conjugated with PECy5 (BD Biosciences, USA) using the required buffers. The cells were fixed/permeabilized buffer (eBioscience, USA). Isotype control or anti-IL17 (PE-conjugated) was used for intracellular staining of Th17 cells (eBiosciences, USA).

\section{Flow Cytometry Assessment}

FACS Calibur system was used for flow cytometry assessment $\left(1 \times 10^{5}\right.$ cells). The data were analyzed by the Cell Quest software (Becton Dickinson, USA).

\section{Real-Time PCR}

RNA extraction kit (Invitek, Germany) was used for total RNA extraction from PBMCs according to the manufacturer's instructions. Reverse transcriptions were performed by RevertAid $^{\mathrm{TM}}$ Hprimers (Germany). Primer-BLAST was performed to verify the specificity of primers. Checking RNA quality was carried out by agarose gel (2\%) electrophoresis that appeared 5.8, 18, and $28 \mathrm{~S}$ bands by a UV light transilluminator. The total volume of all PCR reactions was $20 \mu$ containing $10 \mu \mathrm{l}$ of Real-time PCR -SYBR Green Master Mix (Takara, Japan), $0.3 \mu \mathrm{l}$ of each primer (Table 1), and $7.4 \mu \mathrm{l}$ of RNase-free water. Rotor-Gene Q cycler (Qiagen, Germany) performed real-time PCR. The following standard PCR reaction conditions were used for all transcripts: $10 \mathrm{~min}$ at $95^{\circ} \mathrm{C}, 15 \mathrm{~s}$ at $95^{\circ} \mathrm{C}$ ( 45 cycles), $30 \mathrm{~s}$ at $57^{\circ} \mathrm{C}$, and $1 \mathrm{~min}$ at $60^{\circ} \mathrm{C}$.

Logarithmic dilution series of the total RNA was used to construct 10-fold dilution standard curves for IL-23, IL-6, IL25 , and IL-17A. B2M was used as the internal control gene to normalize mRNA levels between the mentioned cytokines.

\section{ELISA}

Serum VitD3 levels and sex hormones (FSH, LH, Estradiol, Progesterone, and Prolactin) of all subjects were measured by

\begin{tabular}{|c|c|c|c|}
\hline \multirow[t]{2}{*}{ Sex hormone } & \multirow{2}{*}{$\frac{\text { Case group }}{N=20}$} & \multirow{2}{*}{$\frac{\text { Control group }}{\mathrm{N}=20}$} & \multirow[t]{2}{*}{$P$ value } \\
\hline & & & \\
\hline $\mathrm{FSH}(\mathrm{mlU} / \mathrm{ml})$ & $4.6 \pm 3.8$ & $5.4 \pm 3.66$ & 0.36 \\
\hline LH (mlU/ml) & $12.8 \pm 17.8$ & $12.1 \pm 16.4$ & 0.89 \\
\hline Prolactin (ng/ml) & $21.4 \pm 22.8$ & $16.0 \pm 20.6$ & 0.24 \\
\hline Progesterone (ng/ml) & $4.5 \pm 6.8$ & $5.2 \pm 5.4$ & 0.72 \\
\hline Estradiol (pg/ml) & $15.1 \pm 19.0$ & $14.7 \pm 19.3$ & 0.73 \\
\hline
\end{tabular}

ELISA (25-Hydroxy vitamin kit, EuroImmune, Germany) following the manufacturer's protocol.

To measure the levels of cytokines, PBMCs $\left(1 \times 10^{6}\right.$ cells $\left./ \mathrm{ml}\right)$ were cultured in RPMI media (which was described previously) with $50 \mathrm{nM} 1,25 \mathrm{VitD} 3$ or absence of that. Cell culture supernatants were collected after $72 \mathrm{~h}$ and were assayed for concentrations of soluble IL-10, IL-25, IL6, IL-17A, and IL-23 by linked immunosorbent assay using ELISA kits (Biolegend, USA). All samples were run in duplicate. The sensitivity of each assay was as follows: $0.8 \mathrm{pg} / \mathrm{ml}$ (IL-17A), $1.6 \mathrm{pg} / \mathrm{ml}$ (IL-6), $3.5 \mathrm{pg} /$ $\mathrm{ml}$ (IL-25), and $2.45 \mathrm{pg} / \mathrm{ml}$ for IL-23. Coefficients of variation (CV) were $<10 \%$ and $<5 \%$ for inter-assay and intra-assay, respectively.

\section{Analysis of Statistics}

SPSS 16.0 software was used for statistical analysis. Mean data were compared by ANOVA and parametric T-test. P-values of less than 0.05 were regarded as significant. For analyzing all of the inter-group comparisons (the comparison of the studied parameters between the case and the control groups), and for accurate normalization, $1,25 \mathrm{VitD} 3 /$ untreated relative gene expression of between two groups was compared. The data is presented as mean \pm standard error (SE).

\section{RESULTS}

There was no significant difference in mean age between the control group [27.23 \pm 3.5 years (range $24-31$ years)] and women with RSA [29.72 \pm 2.9 years (range $26-32$ years)] $(p>0.05)$. No significant variations were found in the serum level of sexual hormones between the case and the control groups (Table 2). VitD3 serum levels were statically similar between the two groups ( $7.8 \mathrm{ng} / \mathrm{ml} \pm 1.2$ versus $6.9 \mathrm{ng} / \mathrm{ml} \pm 1.0 ; p>0.05$ ).

$1,25 \mathrm{VitD} 3$ increased IL-25 expressions at both protein and mRNA levels in women with URSA relative to the control group.

IL-25 serum levels were significantly lower in women with URSA than in the control group. IL-25 concentrations in the cell 

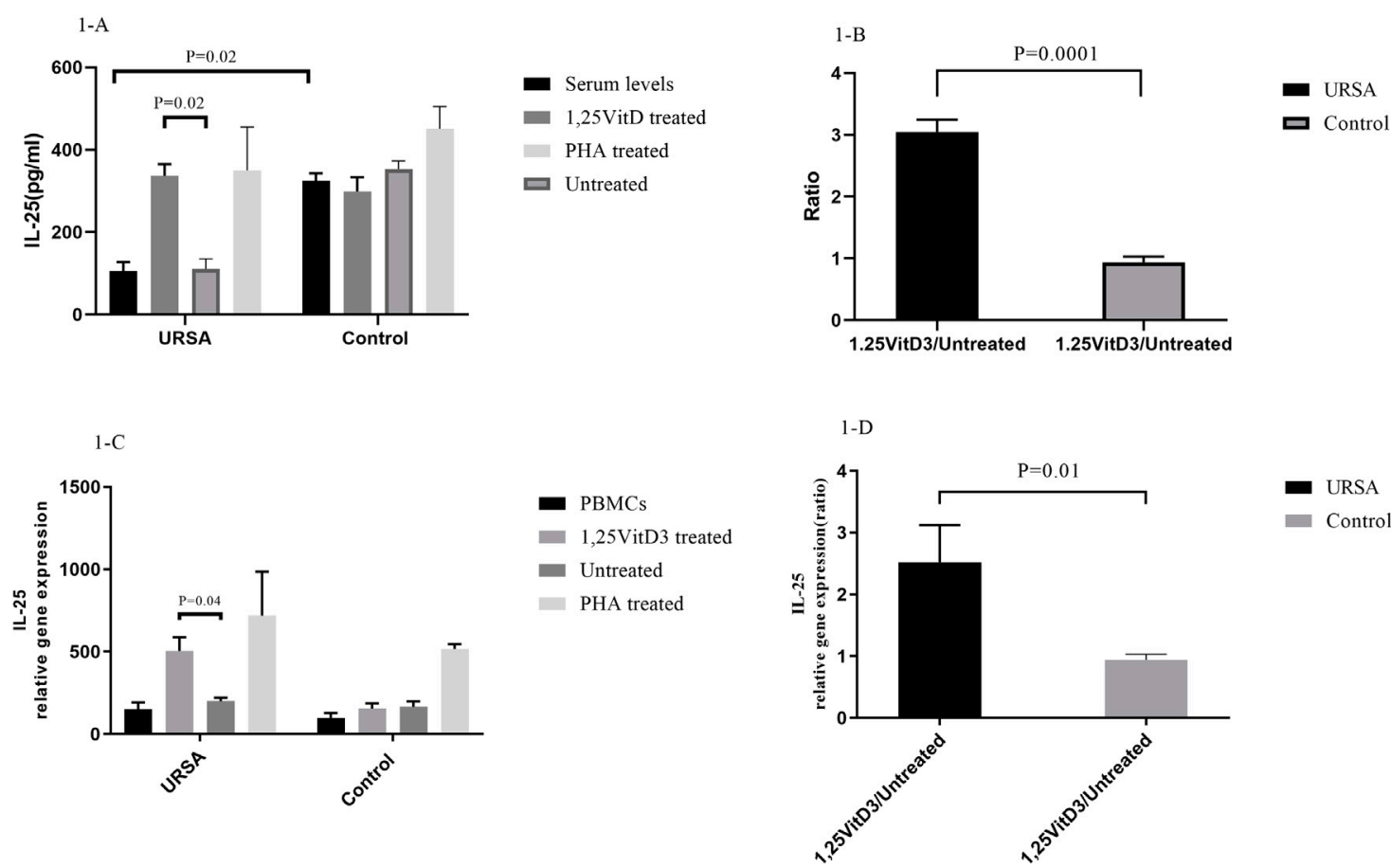

FIGURE 1 | IL-25 expression at mRNA and protein levels. (A). IL-25 serum levels were significantly lower in women with URSA than in the control group. IL-25 concentrations in the cell culture supernatants were significantly lower in women with URSA relative to the control group. (B).1,25VitD3/Untreated relative gene expression for IL-25 levels decreased in women with URSA relative to the control group. (C).1,25VitD3 treatment significantly improved IL-25 expression at mRNA level compared to the untreated PBMCs in URSA patients. (D). 1,25VitD3 treatment significantly improved IL-25 expression at protein level compared to the untreated PBMCs in URSA patients IL-25 relative gene expression (1,25VitD3/untreated) increased in the case group in comparison to the control group (2.52 \pm 0.60 versus. $0.94 \pm 0.09 ; p=0.01 ;$ Figure 1D).
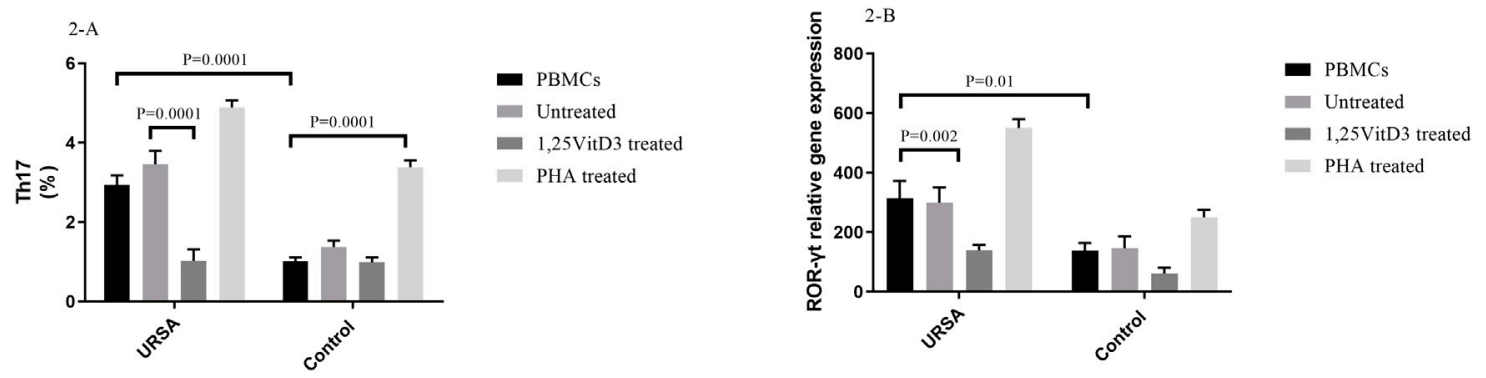

FIGURE 2 | Frequency of Th17 cells and ROR- $\gamma$ t gene expression in URSA and control groups. (A). The proportion of Th17 cells in PBMCs of women with URSA cells were significantly higher compared to the control group. In PBMCs of women with URSA, the percentage of Th17 cells decreased after treatment with 1,25VitD3 relative to untreated PBMCs (B). ROR- $\gamma$ t gene expression was higher in PBMCs of women with URSA than in PBMCs of controls. Treatment with 1,25VitD3 decreased ROR- $\gamma$ t gene expression at the mRNA level relative to untreated PBMCs in women with URSA.

culture supernatants were significantly lower in women with URSA relative to the control group $(105.320 \pm 22.2$ versus. $324.147 \pm 18.500, p=0.02$; Figure 1A). Furthermore, IL-25 levels $(1,25 \mathrm{VitD} 3 /$ Untreated) decreased in women with URSA relative to the control group $(3.05 \pm 0.20$ versus. $0.94 \pm 0.09 ; p=$ 0.0001; Figure 1B).

In the case group, $1,25 \mathrm{VitD} 3$ treatment significantly improved IL-25 expression at both levels of mRNA $(336.82 \pm 28.5$ versus.
$110.14 \pm 25.05 ; p=0.02 ;$ Figure 1C) and protein $(336.82 \pm 28.51$ versus. $110.14 \pm 25.05 ; p=0.02$; Figure 1A) compared to the untreated PBMCs.

The relative gene expression of IL-25 (1,25VitD3/untreated) increased in the case group in comparison to the control group $(2.52 \pm 0.60$ versus. $0.94 \pm 0.09 ; p=0.01$; Figure 1D).

$1,25 \mathrm{VitD} 3$ decreased the percentage of Th17 cells in women with RSA. 

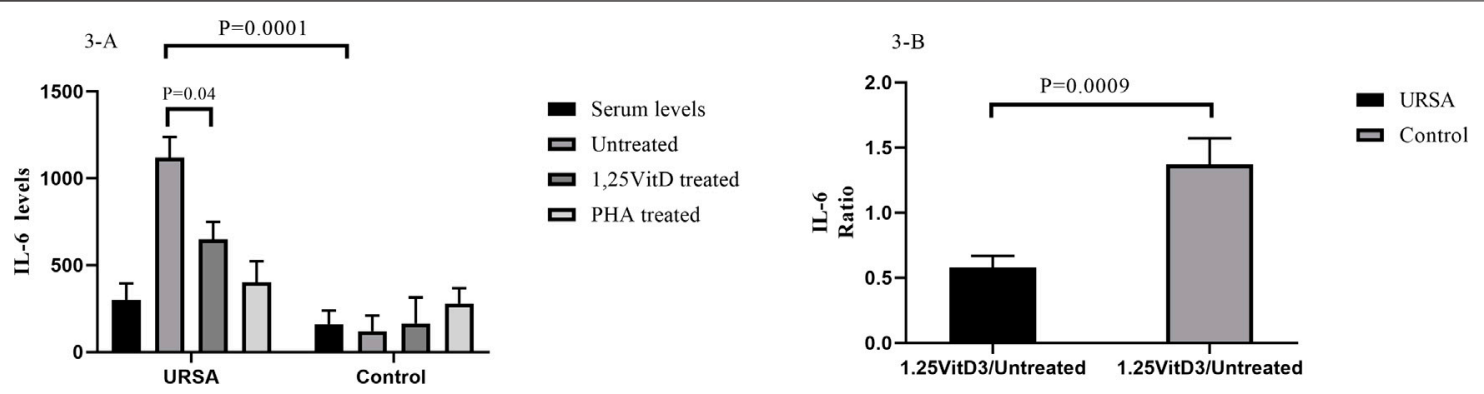

FIGURE 3 | IL-6 levels in serum and cell culture supernatants in women with URSA and the control group (A). IL-6 levels in the cell culture supernatant increased significantly in the case group in comparison to the control group. In cell culture supernatants, 1,25VitD3 treatment decreased IL-6 levels compared to untreated PBMCs only in the case group. (B). IL-6 levels in the presence of 1,25VitD3 to the baseline decreased in women with URSA relative to the control group.

In contrast to PBMCs of the controls, the proportion of Th17 cells in PBMCs of women with URSA cells were significantly higher (2.94 \pm 0.24 vs. $1.01 \pm 0.09, p=0.0001$; Figure 2A). In PBMCs of women with URSA, the percentage of Th17 cells decreased after treatment with $1,25 \mathrm{VitD} 3$ relative to untreated PBMCs ( $1.02 \pm 0.28$ vs. $3.450 \pm 0.34, p=0.0001$; Figure $2 \mathrm{~A}$ ), while $1,25 \mathrm{VitD} 3$ treatment did not change significantly the frequency of Th17 cells compared to untreated PBMCs in the control group $(0.98 \pm 0.12$ vs. $1.37 \pm 0.16, p>0.05$; Figure 2A).

$1,25 \mathrm{VitD} 3$ decreased ROR- $\gamma \mathrm{t}$ gene expression in women with URSA.

ROR- $\gamma$ t gene expression was higher in PBMCs of women with URSA than in PBMCs of controls (314.24 \pm 58.7 vs. $138.14 \pm 25.5$, $p=0.006$; Figure 2B). Treatment with $1,25 \mathrm{VitD} 3$ decreased ROR- $\gamma \mathrm{t}$ gene expression at the mRNA level relative to untreated PBMCs in women with URSA (139.09 \pm 50.99 vs. $316.41 \pm 50.99 ; p=0.002$; Figure 3B) but not in PBMCs from controls (61.25 \pm 19.08 vs. $145.94 \pm 40.21 ; p>0.05$; Figure $2 B)$.

$1,25 \mathrm{VitD} 3$ decreased IL-6 levels in cell culture supernatants in women with URSA relative to the control group.

IL-6 levels in the cell culture supernatant increased significantly in the case group in comparison to the control group $(1,120.28 \mathrm{pg} / \mathrm{ml} \pm 118.67$ versus $1,099.27 \mathrm{pg} / \mathrm{ml} \pm 118.67$; $p=0.0001$; Figure 3A).

In cell culture supernatants, $1,25 \mathrm{VitD} 3$ treatment decreased IL-6 levels compared to untreated PBMCs only in the case group $(649.25 \mathrm{pg} / \mathrm{ml} \pm 99.56$ versus $1,120.28 \mathrm{pg} / \mathrm{ml} \pm 118.67 ; p=0.0009$; Figure 3A), but not in the control group ( $p>0.05$; Figure $3 \mathbf{A}$ ). IL-6 levels in the presence of $1,25 \mathrm{VitD} 3$ to the baseline decreased in women with RSA relative to the control group $(0.63 \pm 0.17$ versus $0.579 \pm 0.09 ; p=0.0009$, Figure $3 \mathrm{~B}$ ).

1,25VitD3 diminished IL-17A levels in women with URSA relative to the control group.

IL-17A serum levels significantly increased in the case group in comparison to the control group $(98.12 \pm 15.4$ versus $48.5 \pm$ $10.5 ; p=0.03$, Figure 4A). IL-17A levels significantly increased in the cell culture supernatants in the case group in comparison to the control group (108.29 \pm 10.4 versus $55.52 \pm 7.53$; $p=0.01$, Figure 4A).

IL-17A levels decreased in the presence of $1,25 \mathrm{VitD} 3$ compared to the absence of that in the case group $(48.6 \mathrm{pg} / \mathrm{ml}$ \pm 10.04 versus $108.29 \mathrm{pg} / \mathrm{ml} \pm 10.40 ; p=0.0006$; Figure 4A). $1,25 \mathrm{VitD} 3 /$ untreated relative gene expression for IL-17A levels non-significantly decreased in women with URSA relative to the control group ( $p>0.05$, Figure 4B).

1,25VitD3 decreased IL-23 levels in women with URSA relative to the control group.

IL-23 serum levels were higher in women with RSA than in the control group $(74 / 4 \mathrm{pg} / \mathrm{ml} \pm 14 / 4$ versus $245 / 45 \mathrm{pg} / \mathrm{ml} \pm 24 / 4 ; p=$ 0.0001; Figure 5A). IL-23 levels were higher in cell culture supernatants in women with RSA than in the control group $(268 / 85 \mathrm{pg} / \mathrm{ml} \pm 18 / 15$ versus $87 / 24 \mathrm{pg} / \mathrm{ml} \pm 12 / 86 ; p=0.0001$; Figure 5B).

$1,25 \mathrm{VitD} 3$ reduced IL-23 levels in the cell culture supernatants in women with URSA in comparison to the control group $(89.26 \mathrm{pg} / \mathrm{ml} \pm 16.47$ versus $162.85 \mathrm{pg} / \mathrm{ml} \pm 19.15 ; \quad p=0.02$; Figure 5B).

\section{DISCUSSION}

Pregnancy is normally considered a state of immunological tolerance, and a break in maternal tolerance may lead to reproductive failure including implantation failure, preeclampsia, preterm birth, and pregnancy loss (Witkin et al., 2011; Ghaneifar et al., 2020). The regulated immune responses are required to protect against harmful pathogens and tolerate a semi-allogeneic fetus expressing paternal antigens in a successful pregnancy (Tsuda et al., 2019). It has been shown that a variety of different immune cells and cytokines maintain maternal immune tolerance to fetal alloantigens during pregnancy (Ali et al., 2020). In a successful pregnancy, a delicate balance has been indicated between various subsets of effector T cells with different secretory cytokines.

In this study, we found that IL-25 levels in serum and supernatants of cell culture were considerably lower in women with URPL than in the healthy women, while IL-17A, IL-23, and IL-6 levels were significantly higher compared to the controls. After PBMCs treatment with 1,25VitD3, IL-25 levels increased, while IL-17A, IL-6, and IL-23 levels decreased in cell culture supernatants in women with URSA relative to the controls. As we previously demonstrated, 1,25VitD3 may reduce the frequency of Th17 cells in PBMCs in women with URPL (Abdollahi et al., 

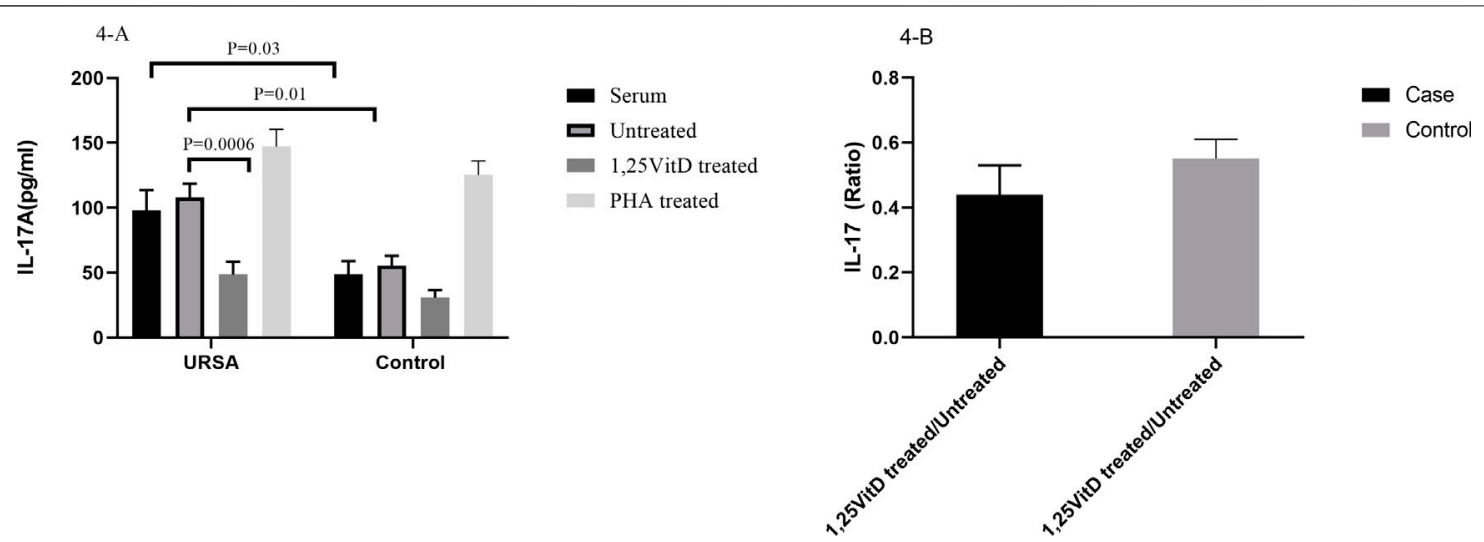

FIGURE 4 | IL-17A levels in serum and cell culture supernatants in women with URSA and the control group (A). IL-17A serum levels significantly increased in the case group in comparison to the control group. IL-17A levels significantly increased in the cell culture supernatants in the case group in comparison to the control group. IL-17A levels decreased in the presence of 1,25VitD3 compared to the absence of that in the case group. (B). IL-17A levels non-significantly decreased in women with URSA relative to the control group.

2020b; Abdollahi et al., 2020c). Inflammation has already been identified as the main contributor to inflammatory disorders and pregnancy complications like recurrent spontaneous abortion (Tincati et al., 2009; Pizzola et al., 2016; Karakuş and Çalışkan, 2020). Th17 cells elicit inflammatory reactions by producing IL$17 \mathrm{~A}$ as the most prominent pro-inflammatory cytokine with a role in URSA occurrence (Veldhoen et al., 2006; Konkel et al., 2017; Fujimoto et al., 2020; Abdollahi et al., 2020d) 63). IL-17A and chemokines including CXCLs attract myeloid cells such as neutrophils to the infection site and activate matrix metalloproteinase, which results in the recruitment of more inflammatory cells such as Th1 and Th17 cells and, as a consequence, a positive loop in amplifying inflammatory reactions (Corrigan et al., 2011; Liu et al., 2016; Abdollahi et al., 2020d).

IL-25 plays an anti-inflammatory role in Th1 and Th17 related disorders, including autoimmune diseases (Selvaraja et al., 2019Fallon et al., 2006). Similar to the URSA, inflammatory responses of Th17 cells play a key role in the immunopathogenesis of autoimmune disorders such as rheumatoid arthritis (RA), inflammatory bowel disease (IBD), and autoimmune encephalomyelitis. It was found that IL-25 inhibited Th17 cell responses via reduction of IL-17A levels and ROR- $\gamma$ t gene expression in PBMCs from patients with RA (Liu et al., 2016; Lavocat et al., 2017). PBMCs are the mixture of mononuclear cells including $\mathrm{T}$ cells and monocytes are the appropriate cells for exploring the underlying cellular and molecular mechanisms in immune-mediated diseases including URSA (Ji et al., 19892019; Abdollahi et al., 2015b; Abdollahi et al., 2016b; Abdollahi et al., 2020a; Abdollahi et al., 2020d; Griffiths et al., 2020). Additionally, IL-25 may suppress Th17 cell responses through downregulation of IL-23, IL-1 $\beta$, and IL-6 expression in activated dendritic cells which may protect mice from severe experimental autoimmune encephalomyelitis (Kleinschek et al., 2007). Furthermore, the deletion of an IL25-dependent gene resulted in increased Th17 cell function by
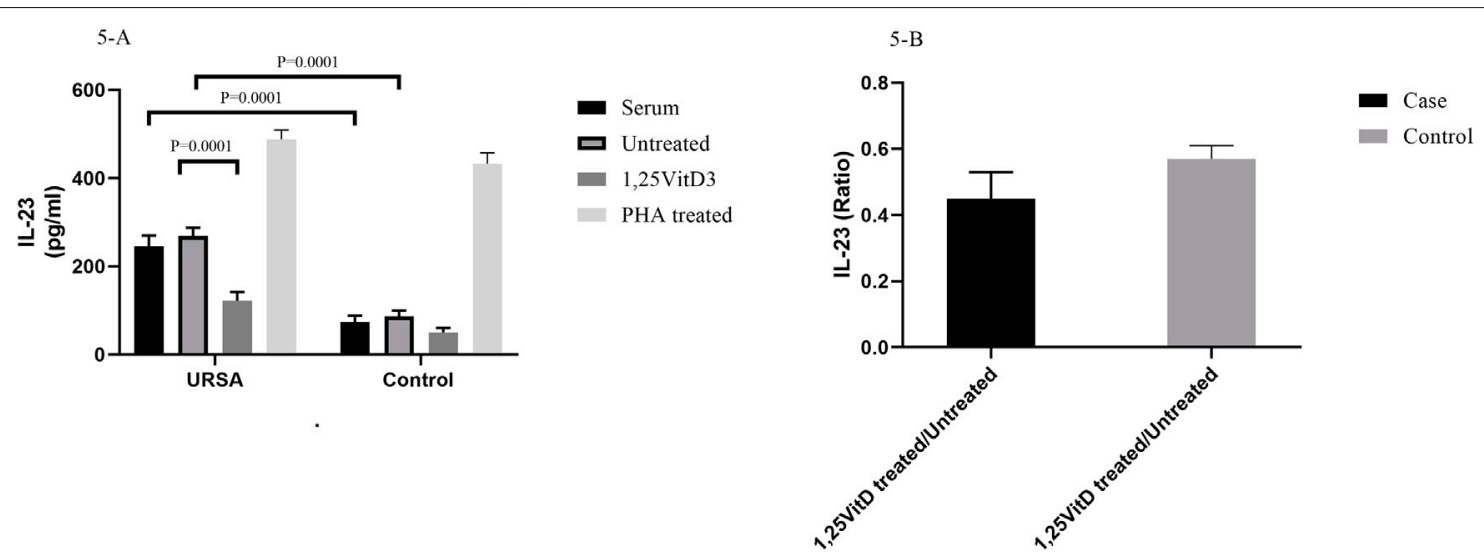

FIGURE 5 | IL-23 levels in serum and cell culture supernatants in women with URSA and the control group (A). IL-23 serum levels were higher in women with RSA than in the control group. IL-23 levels were higher in cell culture supernatants in women with RSA than in the control group. 1,25VitD3 reduced IL-23 levels in the cell culture supernatants in women with URSA in comparison to the control group. (B). IL-123 levels non-significantly decreased in women with URSA relative to the control group. 
secreting pro-inflammatory cytokines such as IL-17A leading to exacerbation of CNS disease (Kleinschek et al., 2007).

Of note, IL-25 has been suggested to support successful pregnancy by promoting the proliferation of decidual $\gamma \delta \mathrm{T}$ cells as well as the release of Th2 cytokines like IL-10 (Wang et al., 2012). This resulted in enhancing maternal tolerance (Corrigan et al., 2011; Wang et al., 2014). Decidual $\gamma \delta$ T cells promote the proliferation and invasion of trophoblast cells as well as suppress the apoptosis via IL-10 production (Fan et al., 2011).

IL-25/IL-17RB expression, as the IL-25 receptor, in decidual cells was reported to decrease in women with recurrent abortion compared to normal pregnant women. In early pregnancy, trophoblast-secreted human chorionic gonadotropin (hCG) increased the expression of IL-25 and IL-17RB in decidual stromal cells (Wang et al., 2014; Zhang et al., 2018). This may lead to increased cell proliferation by activating $\mathrm{c}$ Jun $\mathrm{n}$ terminal kinase (JNK) and protein kinase B (AKT) signals, which could further stimulate DSC proliferation and lead to an increase in the number of DSCs (Wang et al., 2014; Lam et al., 2015).

Additionally, IL-25 may promote human umbilical vein endothelial cell proliferation so it can promote angiogenesis (Corrigan et al., 2011; Wang et al., 2012). In the current study, we indicated that IL-25 levels in the PBMC culture supernatants of the controls were higher than URSA women.

We previously indicated that the active form of VitD3, 1,25VitD3 $(50 \mathrm{~nm})$, increased the frequency of Tregs but decreased parentage of Th17 cells at the same dose in vitro in women experiencing URSA (Abdollahi et al., 2020d). We also implicated that $1,25 \mathrm{VitD} 3$ could increase Treg/Th17 through promoting Treg differentiation and proliferation via upregulation of FOXP3 and GITR gene expressions in women with URSA (Ji et al., 2019; Abdollahi et al., 2020c). FOXP3 is a master transcription factor that regulates Treg development and differentiation (van der Veeken et al., 2020). GITR is a marker of the characteristic of Tregs that induces co-stimulatory signals involved in Treg activity (Abdollahi et al., 2020c). As a result, $1,25 \mathrm{VitD} 3$ acted as a modulator of the immune system through balancing of Treg/Th17 axis in women with URSA.

Here, we assumed that one of the underlying immunomodulatory mechanisms of $1,25 \mathrm{VitD} 3$ may be upregulation of IL-25 expression in PBMCs from patients with URSA. This may inhibit production of Th17 cell inflammatory cytokines including IL-6 and IL-23 in PBMCs from women with URSA.

\section{CONCLUDING REMARKS}

Our findings showed that IL-25 expression was lower, while Th17 cell frequency and related cytokines including IL-17A,

\section{REFERENCES}

Abdollahi, E., Saghafi, N., Rezaee, S. A., Rastin, M., Jarahi, L., Clifton, V., et al. (2020). Evaluation of 1,25(OH)2D3 Effects on FOXP3, ROR-Гt, GITR, and CTLA-4 Gene Expression in the PBMCs of Vitamin D-Deficient Women with
IL-6, and IL-23 were higher in PBMCs from women with URSA, suggesting that decreasing IL-25 expression in the concordance with increasing inflammatory responses of Th17 cells in PBMCs form women with URPL may involve the immunopathogenesis of URSA. $1,25 \mathrm{VitD} 3$ acts as a modulator of the immune system by enhancing the expression of IL-25 that may result in reducing Th17 cells activity. $1,25 \mathrm{VitD} 3$ enhanced the expression of IL-25 as the antiinflammatory cytokine. On the other hand, 1,25VitD3 decreased cytokine expressions that were associated with the differentiation or maintenance of Th17 cells (IL-6 and IL-23). Therefore, 1,25VitD3 may decrease inflammatory responses cells via down regulating if IL-25 expression in PBMCs from women with URSA. However, more studies with the mechanistic view are warranted to establish this concept. It could be an interesting subject for future clinical trials in the field of the immunopathology of URSA to identify molecular pathways in URSA treatment.

\section{DATA AVAILABILITY STATEMENT}

The datasets presented in this study can be found in online repositories. The names of the repository/repositories and accession number(s) can be found below: https://www.ncbi. nlm.nih.gov/.

\section{ETHICS STATEMENT}

The studies involving human participants were reviewed and approved by Mashhad University of Medical Sciences, tafaghodi. The patients/participants provided their written informed consent to participate in this study.

\section{AUTHOR CONTRIBUTIONS}

We are hoping to convince you that this article is a timely subject important to researchers, and we would be greatly obliged if you kindly evaluate this manuscript for publication. This manuscript has been read and approved by all the authors, and all authors listed on the manuscript have agreed to its submission. Each of the authors confirms that this manuscript has not been previously published and is not currently under consideration by any other journal. Additionally, all of the authors have approved the contents of this paper and have agreed to the journal's submission policies.

Unexplained Recurrent Pregnancy Loss (URPL). Iran Biomed. J. 24 (5), 295-305. doi:10.29252/ibj.24.5.290

Abdollahi, E., Rezaee, S. A., Saghafi, N., Rastin, M., Clifton, V., Sahebkar, A., et al. (2020). Evaluation of the Effects of 1,25 Vitamin D3 on Regulatory T Cells and T Helper 17 Cells in Vitamin D-Deficient Women with Unexplained Recurrent Pregnancy Loss. Cmp 13 (4), 306-317. doi:10.2174/1874467213666200303130153 
Abdollahi, E., Saghafi, N., Rezaee, S. A. R., Rastin, M., Jarahi, L., Clifton, V., et al. (2020). Evaluation of 1,25(OH)2D3 Effects on FOXP3, ROR-Гt, GITR, and CTLA-4 Gene Expression in the PBMCs of Vitamin D-Deficient Women with Unexplained Recurrent Pregnancy Loss (URPL). ibj 24 (5), 290-300. doi:10.29252/ibj.24.5.290

Abdollahi, E., Tavasolian, F., Ghasemi, N., Mirghanizadeh, S. A., Azizi, M., Ghoryani, M., et al. (2015). Association between Lower Frequency of R381Q Variant (Rs11209026) in IL-23 Receptor Gene and Increased Risk of Recurrent Spontaneous Abortion (RSA). J. immunotoxicology 12 (4), 317-321. doi:10.3109/1547691x.2014.978056

Abdollahi, E., Tavasolian, F., Momtazi-Borojeni, A. A., Samadi, M., and Rafatpanah, H. (2016). Protective Role of R381Q (Rs11209026) Polymorphism in IL-23R Gene in Immune-Mediated Diseases: A Comprehensive Review. J. immunotoxicology 13 (3), 286-300. doi:10.3109/ $1547691 x .2015 .1115448$

Ali, S., Majid, S., Ali, M. N., Taing, S., Rehman, M. U., and Arafah, A. (2020). Cytokine Imbalance at Materno-Embryonic Interface as a Potential Immune Mechanism for Recurrent Pregnancy Loss. Int. Immunopharmacol, 107118. doi:10.1016/j.intimp.2020.107118

Barad, D. H., Kushnir, V. A., and Gleicher, N. (2017). Focus on Recurrent Miscarriage Phenotypes. Fertil. sterility 107 (1), 64-65. doi:10.1016/ j.fertnstert.2016.10.034

Barati, M., Sinaeian, M., Shokrollahi Barough, M., Pak, F., Semnani, V., Kokhaei, P., et al. (2020). Evaluation of Interleukin 25 and Interleukin 25 Receptor Expression in Peripheral Blood Mononuclear Cells of Breast Cancer Patients and Normal Subjects. J. Interferon Cytokine Res. 40 (3), 139-144. doi:10.1089/ jir.2019.0106

Blomberg Jensen, M., Gerner Lawaetz, J., Andersson, A.-M., Petersen, J. H., Nordkap, L., Bang, A. K., et al. (2016). Vitamin D Deficiency and Low Ionized Calcium Are Linked with Semen Quality and Sex Steroid Levels in Infertile Men. Hum. Reprod. 31 (8), 1875-1885. doi:10.1093/humrep/dew152

Caruso, R., Sarra, M., Stolfi, C., Rizzo, A., Fina, D., Fantini, M. C., et al. (2009). Interleukin-25 Inhibits Interleukin-12 Production and Th1 Cell-Driven Inflammation in the Gut. Gastroenterology 136 (7), 2270-2279. doi:10.1053/ j.gastro.2009.02.049

Corrigan, C. J., Wang, W., Meng, Q., Fang, C., Wu, H., Reay, V., et al. (2011). T-helper Cell Type 2 (Th2) Memory T Cell-Potentiating Cytokine IL-25 Has the Potential to Promote Angiogenesis in Asthma. Proc. Natl. Acad. Sci. 108 (4), 1579-1584. doi:10.1073/pnas.1014241108

Cyprian, F., Lefkou, E., Varoudi, K., and Girardi, G. (2019). Immunomodulatory Effects of Vitamin D in Pregnancy and beyond. Front. Immunol. 10, 2739. doi:10.3389/fimmu.2019.02739

Dabrowski, F., Grzechocinska, B., and Wielgos, M. (2015). The Role of Vitamin D in Reproductive Health-A Trojan Horse or the Golden Fleece? Nutrients 7 (6), 4139-4153. doi:10.3390/nu7064139

Dimitriadis, E., Menkhorst, E., Saito, S., Kutteh, W. H., and Brosens, J. J. (2020). Recurrent Pregnancy Loss. Nat. Rev. Dis. Primers 6 (1), 98-19. doi:10.1038/ s41572-020-00228-z

Divekar, R., and Kita, H. (2015). Recent Advances in Epithelium-Derived Cytokines (IL-33, IL-25, and Thymic Stromal Lymphopoietin) and Allergic Inflammation. Curr. Opin. Allergy Clin. Immunol. 15 (1), 98-103. doi:10.1097/ aci.0000000000000133

Eisman, J. A., Martin, T. J., MacIntyre, I., and Moseley, J. M. (1979). 1,25dihydroxyvitamin-D-receptor in Breast Cancer Cells. Lancet 2 (8156-8157), 1335-1336. doi:10.1016/s0140-6736(79)92816-2

Fahy, J. V. (2015). Type 2 Inflammation in Asthma - Present in Most, Absent in many. Nat. Rev. Immunol. 15 (1), 57-65. doi:10.1038/nri3786

Fallon, P. G., Ballantyne, S. J., Mangan, N. E., Barlow, J. L., Dasvarma, A., Hewett, D. R., et al. (2006). Identification of an Interleukin (IL)-25-dependent Cell Population that Provides IL-4, IL-5, and IL-13 at the Onset of Helminth Expulsion. J. Exp. Med. 203 (4), 1105-1116. doi:10.1084/jem.20051615

Fan, D.-X., Duan, J., Li, M.-Q., Xu, B., Li, D.-J., and Jin, L.-P. (2011). The Decidual Gamma-delta T Cells Up-Regulate the Biological Functions of Trophoblasts via IL-10 Secretion in Early Human Pregnancy. Clin. Immunol. 141 (3), 284-292. doi:10.1016/j.clim.2011.07.008

Figueiredo, A. S., and Schumacher, A. (2016). The T Helper Type 17/regulatory T Cell Paradigm in Pregnancy. Immunology 148 (1), 13-21. doi:10.1111/ imm. 12595
Fort, M. M., Cheung, J., Yen, D., Li, J., Zurawski, S. M., Lo, S., et al. (2001). IL-25 Induces IL-4, IL-5, and IL-13 and Th2-Associated Pathologies In Vivo. Immunity 15 (6), 985-995. doi:10.1016/s1074-7613(01)00243-6

Fujimoto, Y., Kuramoto, N., Yoneyama, M., and Azuma, Y-T. (2020). Interleukin19 as an Immunoregulatory Cytokine. Curr. Mol. Pharmacol. doi:10.2174/ 1874467213666200424151528

Ghaneifar, Z., Yousefi, Z., Tajik, F., Nikfar, B., Ghalibafan, F., Abdollahi, E., et al. (2020). The Potential Therapeutic Effects of Curcumin on Pregnancy Complications: Novel Insights into Reproductive Medicine. IUBMB life 72 (12), 2572-2583. doi:10.1002/iub.2399

Giannubilo, S. R., Landi, B., Pozzi, V., Sartini, D., Cecati, M., Stortoni, P., et al. (2012). The Involvement of Inflammatory Cytokines in the Pathogenesis of Recurrent Miscarriage. Cytokine 58 (1), 50-56. doi:10.1016/j.cyto.2011.12.019

Gonçalves, D. R., Braga, A., Braga, J., and Marinho, A. (2018). Recurrent Pregnancy Loss and Vitamin D: A Review of the Literature. Am. J. Reprod. Immunol. 80 (5), e13022. doi:10.1111/aji.13022

Griffiths, J. I., Wallet, P., Pflieger, L. T., Stenehjem, D., Liu, X., Cosgrove, P. A., et al. (2020). Circulating Immune Cell Phenotype Dynamics Reflect the Strength of Tumor-Immune Cell Interactions in Patients during Immunotherapy. Proc. Natl. Acad. Sci. USA 117 (27), 16072-16082. doi:10.1073/pnas.1918937117

Guerin, L. R., Prins, J. R., and Robertson, S. A. (2009). Regulatory T-Cells and Immune Tolerance in Pregnancy: a New Target for Infertility Treatment? Hum. Reprod. Update 15 (5), 517-535. doi:10.1093/humupd/dmp004

Heyden, E. L., and Wimalawansa, S. J. (2018). Vitamin D: Effects on Human Reproduction, Pregnancy, and Fetal Well-Being. J. Steroid Biochem. Mol. Biol. 180, 41-50. doi:10.1016/j.jsbmb.2017.12.011

Iwakura, Y., Ishigame, H., Saijo, S., and Nakae, S. (2011). Functional Specialization of Interleukin-17 Family Members. Immunity 34 (2), 149-162. doi:10.1016/ j.immuni.2011.02.012

Ji, J., Zhai, H., Zhou, H., Song, S., Mor, G., and Liao, A. (19892019)., 81. New York, NY, e13112. The Role and Mechanism of Vitamin D-Mediated Regulation of Treg/Th17 Balance in Recurrent Pregnancy LossAm. J. Reprod. Immunol. 6 doi:10.1111/aji.13112

Ji, J., Zhai, H., Zhou, H., Song, S., Mor, G., and Liao, A. (2019). The Role and Mechanism of Vitamin D-Mediated Regulation of Treg/Th17 Balance in Recurrent Pregnancy Loss. Am. J. Reprod. Immunol. 81 (6), e13112. doi:10.1111/aji.13112

Karakuş, M. M., and Çalışkan, U. K. (2020). Phytotherapeutic and Natural Compound Applications for Age-Related, Inflammatory and Serious Eye Ailments. Ankara, Turkey: Current Molecular Pharmacology.

Kim, M. R., Manoukian, R., Yeh, R., Silbiger, S. M., Danilenko, D. M., Scully, S., et al. (2002). Transgenic Overexpression of Human IL-17E Results in Eosinophilia, B-Lymphocyte Hyperplasia, and Altered Antibody Production. J. Am. Soc. Hematol. 100 (7), 2330-2340. doi:10.1182/blood-2002-01-0012

Kleinschek, M. A., Owyang, A. M., Joyce-Shaikh, B., Langrish, C. L., Chen, Y., Gorman, D. M., et al. (2007). IL-25 Regulates Th17 Function in Autoimmune Inflammation. J. Exp. Med. 204 (1), 161-170. doi:10.1084/jem.20061738

Kolls, J. K., and Lindén, A. (2004). Interleukin-17 Family Members and Inflammation. Immunity 21 (4), 467-476. doi:10.1016/j.immuni.2004.08.018

Konkel, J. E., Zhang, D., Zanvit, P., Chia, C., Zangarle-Murray, T., Jin, W., et al. (2017). Transforming Growth Factor- $\beta$ Signaling in Regulatory T Cells Controls $\mathrm{T}$ Helper-17 Cells and Tissue-specific Immune Responses. Immunity 46 (4), 660-674. doi:10.1016/j.immuni.2017.03.015

Lam, M., Hull, L., Imrie, A., Snidvongs, K., Chin, D., Pratt, E., et al. (2015). Interleukin-25 and Interleukin-33 as Mediators of Eosinophilic Inflammation in Chronic Rhinosinusitis. Am. J. Rhinol Allergy 29 (3), 175-181. doi:10.2500/ ajra.2015.29.4176

Lavocat, F., Ndongo-Thiam, N., and Miossec, P. (2017). Interleukin-25 Produced by Synoviocytes Has Anti-inflammatory Effects by Acting as a Receptor Antagonist for interleukin-17A Function. Front. Immunol. 8, 647. doi:10.3389/fimmu.2017.00647

Lee, J., Ho, W.-H., Maruoka, M., Corpuz, R. T., Baldwin, D. T., Foster, J. S., et al. (2001). IL-17E, a Novel Proinflammatory Ligand for the IL-17 Receptor Homolog IL-17Rh1. J. Biol. Chem. 276 (2), 1660-1664. doi:10.1074/ jbc.m008289200

Licona-Limón, P., Kim, L. K., Palm, N. W., and Flavell, R. A. (2013). TH2, Allergy and Group 2 Innate Lymphoid Cells. Nat. Immunol. 14 (6), 536-542. doi:10.1038/ni.2617 
Liu, D., Cao, T., Wang, N., Liu, C., Ma, N., Tu, R., et al. (2016). IL-25 Attenuates Rheumatoid Arthritis through Suppression of Th17 Immune Responses in an IL-13-dependent Manner. Sci. Rep. 6 (1), 36002-36011. doi:10.1038/srep36002

Luk, J., Torrealday, S., Neal Perry, G., and Pal, L. (2012). Relevance of Vitamin D in Reproduction. Hum. Reprod. 27 (10), 3015-3027. doi:10.1093/humrep/des248

Makishima, M., Lu, T. T., Xie, W., Whitfield, G. K., Domoto, H., Evans, R. M., et al. (2002). Vitamin D Receptor as an Intestinal Bile Acid Sensor. Science 296 (5571), 1313-1316. doi:10.1126/science.1070477

Mantani, P. T., Dunér, P., Bengtsson, E., Alm, R., Ljungcrantz, I., Söderberg, I., et al. (2015). IL-25 Inhibits Atherosclerosis Development in Apolipoprotein E Deficient Mice. PloS one 10 (1), e0117255. doi:10.1371/journal.pone.0117255

Martens, P.-J., Gysemans, C., Verstuyf, A., and Mathieu, C. (2020). Vitamin D's Effect on Immune Function. Nutrients 12 (5), 1248. doi:10.3390/nu12051248

Muyayalo, K. P., Huang, D. H., Zhao, S. J., Xie, T., Mor, G., and Liao, A. H. (2020). COVID-19 and Treg/Th17 Imbalance: Potential Relationship to Pregnancy Outcomes. Am. J. Reprod. Immunol. 84 (5), e13304. doi:10.1111/aji.13304

Pan, G., French, D., Mao, W., Maruoka, M., Risser, P., Lee, J., et al. (2001). Forced Expression of Murine IL-17E Induces Growth Retardation, Jaundice, a Th2Biased Response, and Multiorgan Inflammation in Mice. J. Immunol. 167 (11), 6559-6567. doi:10.4049/jimmunol.167.11.6559

Pei, C.-Z., Kim, Y. J., and Baek, K.-H. (2019). Pathogenetic Factors Involved in Recurrent Pregnancy Loss from Multiple Aspects. Obstet. Gynecol. Sci. 62 (4), 212-223. doi:10.5468/ogs.2019.62.4.212

Pizzola, C., M. Rizvi, S. S., and Joshi, M. (2016). A new era of Immunotherapy in Prostate Cancer. Cmp 9 (3), 217-225. doi:10.2174/ 1874467208666150716120551

Saito, S., Nakashima, A., Shima, T., and Ito, M. (2010). Th1/Th2/Th17 and Regulatory T-Cell Paradigm in Pregnancy. Am. J. Reprod. Immunol. 63 (6), 601-610. doi:10.1111/j.1600-0897.2010.00852.x

Selvaraja, M., Abdullah, M., Arip, M., Chin, V. K., Shah, A., and Amin Nordin, S. (2019). Elevated Interleukin-25 and its Association to Th2 Cytokines in Systemic Lupus Erythematosus with Lupus Nephritis. PloS one 14 (11), e0224707. doi:10.1371/journal.pone.0224707

Tincati, C., Monforte, A., and Marchetti, G. (2009). Immunological Mechanisms of Interleukin-2 (IL-2) Treatment in HIV/AIDS Disease. Cmp 2 (1), 40-45. doi:10.2174/1874467210902010040

Tsuda, S., Nakashima, A., Shima, T., and Saito, S. (2019). New Paradigm in the Role of Regulatory T Cells during Pregnancy. Front. Immunol. 10, 573. doi:10.3389/ fimmu.2019.00573

Umar, M., Sastry, K., and Chouchane, A. (2018). Role of Vitamin D beyond the Skeletal Function: a Review of the Molecular and Clinical Studies. Ijms 19 (6), 1618. doi:10.3390/ijms19061618

van der Veeken, J., Glasner, A., Zhong, Y., Hu, W., Wang, Z-M., Bou-Puerto, R., et al. (2020). The Transcription Factor Foxp3 Shapes Regulatory T Cell Identity by Tuning the Activity of Trans-acting Intermediaries. Immunity. doi:10.1016/ j.immuni.2020.10.010

Veldhoen, M., Hocking, R. J., Atkins, C. J., Locksley, R. M., and Stockinger, B. (2006). TGF $\beta$ in the Context of an Inflammatory Cytokine Milieu Supports De Novo Differentiation of IL-17-Producing T Cells. Immunity 24 (2), 179-189. doi:10.1016/j.immuni.2006.01.001
Veldurthy, V., Wei, R., Oz, L., Dhawan, P., Jeon, Y. H., and Christakos, S. (2016). Vitamin D, Calcium Homeostasis and Aging. Bone Res. 4 (1), 16041-16047. doi:10.1038/boneres.2016.41

Vijayendra Chary, A., Hemalatha, R., Seshacharyulu, M., Vasudeva Murali, M., Jayaprakash, D., and Dinesh Kumar, B. (2015). Vitamin D Deficiency in Pregnant Women Impairs Regulatory T Cell Function. J. Steroid Biochem. Mol. Biol. 147, 48-55. doi:10.1016/j.jsbmb.2014.11.020

Wang, W., Fan, Y. Q., Lv, Z., Yao, X. J., Wang, W., Huang, K. W., et al. (2012). Interleukin-25 Promotes Basic Fibroblast Growth Factor Expression by Human Endothelial Cells through Interaction with IL-17RB, but Not IL-17RA. Clin. Exp. Allergy 42 (11), 1604-1614. doi:10.1111/j.1365-2222.2012.04062.x

Wang, W., Sung, N., Gilman-Sachs, A., and Kwak-Kim, J. (2020). T Helper (Th) Cell Profiles in Pregnancy and Recurrent Pregnancy Losses: Th1/Th2/Th9/ Th17/Th22/tfh Cells. Front. Immunol. 11, 2025. doi:10.3389/ fimmu.2020.02025

Wang, Y.-H., Angkasekwinai, P., Lu, N., Voo, K. S., Arima, K., Hanabuchi, S., et al. (2007). IL-25 Augments Type 2 Immune Responses by Enhancing the Expansion and Functions of TSLP-DC-activated Th2 Memory Cells. J. Exp. Med. 204 (8), 1837-1847. doi:10.1084/jem.20070406

Wang, Y., Zhang, Y., Li, M.-Q., Fan, D.-X., Wang, X.-H., Li, D.-J., et al. (2014) Interleukin-25 Induced by Human Chorionic Gonadotropin Promotes the Proliferation of Decidual Stromal Cells by Activation of JNK and AKT Signal Pathways. Fertil. Sterility 102 (1), 257-263. doi:10.1016/ j.fertnstert.2014.03.025

Witkin, S., Linhares, I., Bongiovanni, A., Herway, C., and Skupski, D. (2011). Unique Alterations in Infection-Induced Immune Activation during Pregnancy. BJOG: Int. J. Obstet. Gynaecol. 118 (2), 145-153. doi:10.1111/ j.1471-0528.2010.02773.X

Zhang, Y., Wang, Y., Li, M. Q., Duan, J., Fan, D. X., and Jin, L. P. (2018). IL-25 Promotes Th2 Bias by Upregulating IL-4 and IL-10 Expression of Decidual $\gamma \delta$ T Cells in Early Pregnancy. Exp. Ther. Med. 15 (2), 1855-1862. doi:10.3892/ etm. 2017.5638

Conflict of Interest: The authors declare that the research was conducted in the absence of any commercial or financial relationships that could be construed as a potential conflict of interest.

Publisher's Note: All claims expressed in this article are solely those of the authors and do not necessarily represent those of their affiliated organizations, or those of the publisher, the editors, and the reviewers. Any product that may be evaluated in this article, or claim that may be made by its manufacturer, is not guaranteed or endorsed by the publisher.

Copyright (c) 2021 Li, Saghafi, Ghaneifar, Rezaee, Rafatpanah and Abdollahi. This is an open-access article distributed under the terms of the Creative Commons Attribution License (CC BY). The use, distribution or reproduction in other forums is permitted, provided the original author(s) and the copyright owner(s) are credited and that the original publication in this journal is cited, in accordance with accepted academic practice. No use, distribution or reproduction is permitted which does not comply with these terms. 